Otterbein University

Digital Commons @ Otterbein

Religion \& Philosophy Faculty Scholarship

Religion \& Philosophy

$12-2011$

\title{
The Incorrigible Social Meaning of Video Game Imagery
}

Stephanie Patridge

Otterbein University

Follow this and additional works at: https://digitalcommons.otterbein.edu/religion_fac

Part of the Philosophy Commons

\section{Repository Citation}

Patridge, Stephanie, "The Incorrigible Social Meaning of Video Game Imagery" (2011). Religion \&

Philosophy Faculty Scholarship. 3.

https://digitalcommons.otterbein.edu/religion_fac/3

This Article is brought to you for free and open access by the Religion \& Philosophy at Digital Commons @ Otterbein. It has been accepted for inclusion in Religion \& Philosophy Faculty Scholarship by an authorized administrator of Digital Commons @ Otterbein. For more information, please contact digitalcommons07@otterbein.edu. 


\title{
The incorrigible social meaning of video game imagery
}

\author{
Stephanie Patridge
}

Published online: 26 September 2010

(C) Springer Science+Business Media B.V. 2010

\begin{abstract}
In this paper, I consider a particular amoralist challenge against those who would morally criticize our single-player video play, viz., "come on, it's only a game!" The amoralist challenge with which I engage gains strength from two facts: the activities to which the amoralist lays claim are only those that do not involve interactions with other rational or sentient creatures, and the amoralist concedes that there may be extrinsic, consequentialist considerations that support legitimate moral criticisms. I argue that the amoralist is mistaken and that there are non-consequentialist resources for morally evaluating our singleplayer game play. On my view, some video games contain details that anyone who has a proper understanding of and is properly sensitive to features of a shared moral reality will see as having an incorrigible social meaning that targets groups of individuals, e.g., women and minorities. I offer arguments to support the claim that there are such incorrigible social meanings and that they constrain the imaginative world so that challenges like "it's only a game" lose their credibility. I also argue that our responses to such meanings bear on evaluations of our character, and in light of this fact video game designers have a duty to understand and work against the meanings of such imagery.
\end{abstract}

Keywords Ethics - Video games - Applied ethics - Race · Gender Aesthetics V Virtual pedophilia

S. Patridge $(\bowtie)$

Department of Philosophy, Otterbein University,

Westerville, OH 43081, USA

e-mail: spatridge@otterbein.edu

\section{Single-player video game play and the challenge of amoralism}

To the extent that our game play puts us in contact with agents who are either rational or sentient, it is the proper subject of moral evaluation. Such contact might be made when one plays a multiplayer game, ${ }^{1}$ when one purchases game currency or goods from a "gold farm,", or when one purchases a game from a company with a poor environmental record. While in each of these situations there are considerations that clearly place our activities within the scope of the moral, my focus here is exclusively on our single-player video game play itself. In this more narrow context, one might be tempted to conclude that our activities are not within the scope of the moral because there are no salient moral considerations to speak of. To see this point more forcefully, consider that with the exception of the player herself, the characters that populate singleplayer game worlds are neither rational nor sentient. As a result, players can neither fail to respect them nor harm them; at best, it seems that players can simulate disrespecting or harming creatures that are roughly like them. In light of this, one might think that morality has very little to say about our single-player in-game activities, and so advocate amoralism about such game play.

Amoralism in such a narrowly circumscribed context has a few virtues. First, it can accommodate our ordinary moral judgments in a wide-range of cases. For example, we might think it odd to claim that it is immoral to enjoy simulating shooting one's enemies while playing No One Lives Forever, even though we might think that enjoying actually shooting one's enemies would expose a flaw in our

\footnotetext{
${ }^{1}$ Raiter and Warner (2005).

2 Ibid.
} 
character. Similarly, we might think it odd were someone recommended to us as a person of noble character on the basis of her treatment of her citizens in Civilization III. We can think of countless number of similar assessments, assessments that would be perfectly cogent in a real world context but would be misplaced in the context of a singleplayer video game. Second, once we recognize that widening the context of our activity to include our interactions with actual sentient and rational creatures places our activities squarely in the realm of the moral, this narrow form of amoralism appears less radical. For example, amoralism about single-player video game play is consistent with a substantive moral theory of MMOGs. Third, a commitment to amoralism even in this narrow context does not entail a wholesale rejection of evaluation of our singleplayer video game play. It is open to the amoralist to point out that there are non-moral gamer values or virtues that are expressive of playing well, though what it means to play well will be made sense of in distinctly non-moral terms.

Still, the representational content of at least some video games strikes many of us as especially morally worrisome, despite their apparent fictionality. Consider, for example, that in playing the game Custer's Revenge we are asked to navigate a representation of General Custer through a hail of arrows toward a target that is a representation of a naked, Native-American woman who is tied to a pole. If we successfully reach our target, then our reward is that our character-Custer-simulates a rape of the Native-American character as our point total rises. Certainly, it seems, morality must have something interesting to say about this game. One way to resolve the apparent tension between the amoralist challenge and our intuitions about games like Custer's Revenge is to point to indirect harms that can result from enjoying even simulations of activities like rape. In this spirit, one might cite evidence to support the claim that playing Custer's Revenge makes us more violent, insensitive, rash, sexist, or racist. If challenges of this sort can be sustained, we have a compelling, though extrinsic, reason to avoid playing at least some video games-a reason that even the amoralist will have to concede. After all, if fictional activities have real-world ramifications, then there is no reason to deny the legitimacy of such considerations. What the amoralist must deny is that there are legitimate intrinsic grounds for moral assessment of such activities. It is this claim that I aim to undermine here. I think that there are also legitimate intrinsic moral reasons to avoid playing video games like Custer's Revenge that can be illuminated by adopting a virtue-theoretic perspective. On my view, some video games contain details that anyone who has a proper understanding of and is properly sensitive to features of a shared moral reality will see as having an incorrigible social meaning that targets groups of individuals, in this case women and minorities. I offer arguments to support the claim that there are such incorrigible social meanings and that they constrain the imaginative world so that challenges like "it's only a game" lose their credibility. I also argue that our responses to such meanings bear on evaluations of our character, and in light of this fact video game designers have a duty to understand and work against the meanings of such imagery. ${ }^{3}$ If I am right, then even a very narrowly constrained amoralism-amoralism about intrinsic, evaluative considerations-ought to be rejected.

\section{Virtual wrongs and their consequences for virtue}

Some video game ethicists who adopt a virtue ethical perspective focus on the benefits and harms that accrue to a player's character via her game play. For example, in an attempt to show that the mere fictionality of a video game is insufficient to push it out of the realm of the moral, Matt McCormick argues that it would be morally wrong for someone to use a virtual reality suite to engage in virtualpedophilia, virtual-genocide, or virtual-rape because by "participating in simulations of excessive, indulgent, and wrongful acts, we are cultivating the wrong sort of character...you do harm to yourself in that you erode your virtue, and you distance yourself from your goal of eudaimonia." ${ }^{4}$ In an effort to extend McCormick's analysis, Mark Coeckelbergh argues that "[t]he moral problem, then, is not so much with committing virtual moral acts as such, but with doing that repeatedly, with training these acts." 5 In a similar vein, Monique Wonderly argues that the "problem with [violent video] games is that they may damage our empathetic faculties, and in so doing, they may be directly harming our centers of moral judgment. ${ }^{6} \mathrm{Mi}-$ quel Sicart claims that " $[w]$ hen defining the player as a virtuous being, I use the Aristotelian concept of practical wisdom, or phronesis, to refer to how a player determines which choices can further develop her virtues as a player." 7 Insofar these theorists treat the having of a proper character as the end of action, as something to be maximized, promoted, or aimed at in some way they appear to endorse a version of virtue-consequentialism.

However, the trend amongst contemporary virtue theorists is to interpret virtue theory primarily as moral theory

\footnotetext{
${ }^{3}$ Hereafter, I shall refer to 'single-player video game play' by the less cumbersome 'game play,' though throughout I focus only on this narrow range of video game activities, unless I note otherwise.

4 McCormick (2001).

5 Coeckelbergh (2007).

${ }^{6}$ Wonderly (2008).

${ }^{7}$ Sicart (2009).
} 
that emphasizes the source of an action understood in terms of virtuous traits of character, rather than the consequences that accrue to one's character. ${ }^{8}$ Despite a fair amount of disagreement amongst virtue theorists over exactly how to specify the relationship between the virtues and right action, virtue theorists tend to agree that an action is right if and only if it is expressive of virtue. So, for example, an action will be wrong if all-things-considered it is expressive of cruelty, and right if it is all-things-considered expressive of kindness. Though virtue theorists certainly care about cultivating a proper character, and so will care about the kinds of considerations that are raised in much of the ethics literature on video games that focuses on the virtues, such concerns are not the primary focus of virtue theory. What is particularly attractive about virtue theory for my purposes is that it provides non-consequential resources for assessing the moral status of our in-game activities, resources that I avail myself of in this project. To help illustrate this point, let us again consider McCormick's example of virtual pedophilia. In a case like this one, our moral disgust is not aimed at the virtual pedophile's wanton disregard for the health of her character as McCormick's analysis suggests. Instead, it is aimed at the current status of her character. There must be something wrong, antecedently, with anyone who would engage in such an activity for pleasure, independent of the consequences that might accrue to herself or others. ${ }^{9}$ If you are skeptical of this point, I invite you to imagine what you would think of your friend should you find her coming out of the virtual reality suite announcing "I just had great time in there. You can even have sex with virtual children. But hey, no worries, they aren't real." Assuming that we did not have prior knowledge of our friend's virtual-exploits, I think that it is safe to say that for most of us our attitude toward our friend would be significantly diminished. This person cannot be the person that we thought she was. In some cases, we might even think that our friend's willingness or ability to engage in such an activity is a reason to end the friendship altogether. It would not be that we were worried that such behavior would make our friend a worse person, though it might and this is certainly a morally salient consideration. More to the point, however, we

\footnotetext{
${ }^{8}$ See, for example, Rosalind Hursthouse's seminal articulation and defense of virtue theory. Hursthouse (1999).

${ }^{9}$ If our judgments can be sustained in such a case, this suggests that there are resources for moral criticism of the virtual pedophile even if there is little reason to support the claim that such activities harm actual children as Neil Levy argues. See, Levy (2002). Further, it suggests that there are resources for moral criticism even if, contra Levy, virtual pedophilia harms virtually no one as Peter Singer argues. See, Singer (2007).
}

would worry that our friend is a worse person than we thought she was. Anyone who would do that must be. ${ }^{10}$

\section{Virtual wrongs and non-consequential assessment}

\section{A guiding case: Custer's Revenge}

What exactly does the virtual-pedophilia case establish? Minimally, I think that it establishes that some activities that are aimed at fictional entities and so are in some sense simulated, expose a flaw in the agent's character: a virtuous agent would not undertake such an activity for the sake of pleasure, sexual or otherwise. So, it at least makes room for the possibility that our game play, fictionalized as it is, might also be expressive of a flaw in our character. Still, it is not clear how to move from this highly particularized case to general claims about the morality of single-player video game play. This is so because we do not have a clear picture of what exactly has gone wrong with the virtual pedophile. To make further progress in this area, we need to know two things. First, when are our video game activities expressive of our character? Second, in what way are they so expressive? In an attempt to help answer these questions, let us consider the following scenario: your friend asks you to play the game that I mentioned at the outset of this essay, Custer's Revenge. ${ }^{11}$ The goal of Custer's Revenge, your friend explains, is to save another character that is held captive. As you begin to play, you notice two things. First, your character, General Custer, is under attack by a hail of arrows shot by native-Americans. Second, the character that you are to save is a nativeAmerican woman who is unclothed and tied to a pole. While you worry about the possible racial and gender insensitivity of this game, you continue playing. ${ }^{12}$ After all, you reason, it's only a game and you do not want to get into it with your friend. However, when you navigate Custer through the onslaught of arrow attacks to reach your target,

\footnotetext{
${ }^{10}$ Morgan Luck argues that in some cases virtual pedophilia might lead to a reduction in harm. I agree that in a case in which virtual pedophilia is a necessary means to preventing actual pedophilia, it seems that all-things-considered the pedophile ought to engage in virtual pedophilia. Nevertheless, I think that such an activity exposes a substantive flaw in the pedophile's character. Virtuous agents would not need such cathartic experiences. See, Luck (2009).

${ }^{11}$ Custer's Revenge was released in 1982 for Atari by Mystique, a company that produced a number of video games with graphic sexual content.

12 Phillip Brey argues that "[t]he principal moral importance of [representations that are biased] is that they may induce false or biased beliefs in users that may ultimately have undesirable practical consequences." Brey (1999). While Brey may be right, the line of reasoning that $\mathrm{I}$ am pursuing here is a distinctly non-consequential one.
} 
you find that part of your/Custer's reward is to "rape" the native-American woman. ${ }^{13}$

I suspect that many of us would be somewhat puzzled to find ourselves put in such a position, especially by someone that we take to be our friend. Of obvious significance here is that Custer's Revenge invites us to be entertained by part of the game's reward, a representation of a rape of a Native-American woman. We might initially consider that our friend is only pulling our leg, or trying to make a moral point. But, after having ruled out such explanations, I think that many of us would feel compelled to say something to our friend about the way in which this game makes us morally uneasy. We should not, it seems, enjoy representations like that. Still, if upon voicing our unease, our friend responded to our complaint by claiming "hey, come on, it's only a game. You know that I am not a racist or sexist." to merely insist that we should not enjoy representations like that seems, if not unconvincing, certainly unilluminating. Moreover, this challenge is made more difficult by the fact that many games contain representations of immorality that are not similarly morally worrisome. For example, setting aside the issue of the effects that playing games might have on those who play them, I doubt that most of us would find much of the violent content that we find in the average first-person shooter, fictionalized as it is, morally troubling per se. ${ }^{14}$ We might find such games juvenile, or in bad taste, or even boring, but not morally objectionable. Further, it will not do to point out that in playing Custer's Revenge it is we who enact the wrong represented and this is morally relevant, ${ }^{15}$ since many games that are not morally troubling also invite us to do this.

What I want to know then is what it is about a game like Custer's Revenge that makes it morally worrisome, given that many other games contain representations of immorality that are not. This is the crux of the matter: on what grounds can we say that it is permissible to enjoy some representations of immorality, but not others? In what follows, I quickly consider one possible solution to the "it's only a game" challenge that I think is unsatisfactory because it fails to take seriously the reasonable thought that sometimes being fictional makes a moral difference. Still, this view does provide us guidance insofar as it opens up

\footnotetext{
13 Strictly speaking, in the actual game Custer simulates sexual intercourse with the native-American woman while she is still tied to the pole, though I doubt many will have difficultly conceiving of this as a depiction of rape.

${ }^{14}$ I do not mean to deny that there are legitimate consequential considerations that one might cite here. I only intend to set these matters aside in order to expose a different kind of moral evaluation that has been underexplored.

15 For an argument that in-game activities are our activities see Vellemen (2008).
}

the possibility that even in fictional contexts, our attitudinal responses say something morally important about the kind of person that we are. In the final section, I suggest a way of thinking about these kinds of characterological evaluations that is non-consequential and sensitive to context.

Fictional activities and actual attitudes

One might respond to the "it's only a game" challenge by pointing out that when we play video games we experience emotions and other attitudinal states that are not fictional. For example, often when we play video games we are amused, happy, frustrated, dissatisfied, and even on occasion mortified. We do not merely pretend to experience such emotional attitudes. Some philosophers have argued that the fact that our attitudes and emotions are not feigned suggests that they are expressive of our actual commitments, moral and otherwise. ${ }^{16}$ As Berys Gaut puts the point in another context,

I can criticize someone for taking pleasure in others' pain, for being amused by sadistic cruelty, for being angry at someone when she has done no wrong, for desiring the bad. The same is true when responses are directed at fictional events, for these responses are actual, not just imagined ones. ${ }^{17}$

On Gaut's view, we should not respond positively to a morally negative scene and vice versa, regardless of the ontological status of subjects of the scene. If our attitudinal responses to video games are expressive of our actual commitments, then we are subject to a straightforward kind of moral appraisal in light these attitudes. That is, our attitudes and emotions are subject to roughly the same moral evaluation in fictional contexts as in actual contexts. So, just as we can be morally criticized for finding an instance of racial injustice amusing, we can be criticized for enjoying the unseemly content in Custer's Revenge.

One virtue of views like these is that they provide a compelling explanation of the wrongness of virtual-pedophilia. It is exceedingly difficult to imagine an agent that enjoys virtual pedophilia but does not have unseemly sexual urges toward children, however weak. But, how well does this account make sense of our friend's response to Custer's Revenge? Certainly, it is possible that our friend's enjoyment is expressive of his unsavory attitudes towards women, minorities, or both, despite his protestations otherwise. After all, we are not always in the best position to know our own moral commitments. But, what if we have no other evidence to suggest that he is racist or sexist except his enjoyment of Custer's Revenge? Are we

\footnotetext{
${ }^{16}$ See, for example, Gaut (2002) and Walton (1997).

${ }^{17}$ Gaut, ibid.
} 
prepared to infer from this single instance that our friend is wrong about his own attitudes, and in fact he does have racist and/or sexist attitudes? Certainly, if we notice a pattern of attitudinal responses, then the strength of such an inference would increase. But, if we are to accept this view, then we must also accept the immediate inference from the fact that our friend's enjoyment is aimed at this morally worrying representational content to the claim that he is either racist, sexist, or both. At the very least, I think that many readers will be uneasy about the supposed immediacy of such an inference. Still, even those of us who might be willing to countenance such a failing in even this case, would likely be unwilling to make a similar inference in any number of structurally similar cases. ${ }^{18}$ Consider, for example, the game Mafia Wars. The fact that we enjoy this game seems to say nothing all by itself about our moral attitude toward organized crime, just as our enjoyment of Farmville likely says nothing about our attitude toward farming. This is not to say that the attitudes and emotions that we experience in video game contexts never say anything morally interesting about us, I think that they do. My only claim here is that in many cases they do not, or at least not in the way that this family of views requires. Insofar as such views commit us to the claim that as a matter of course they do, they represent an over-moralizing of our video game play. ${ }^{19}$

Still, as I suggested earlier, I think that Gaut is right that our intentional attitudes even in imaginative contexts are the proper subject of moral evaluation. Where he has gone wrong is in thinking that the fact that an attitude is mobilized in an imaginative context never makes a moral difference. It does. The cases offered above support this point. What we need then is to think more carefully about the kinds of non-consequential considerations that are morally salient for determining if we should play a particular firstperson video game for fun. In what follows, I offer an account of some such considerations. I argue in a step-wise fashion that some otherwise imaginative representations, including those that we find in video games, have what I call incorrigible social meanings. These meanings operate to limit the range of reasonable interpretations of fictionalized representations, so that anyone who has a proper understanding of and is properly sensitive to particular features of the moral landscape will see some video game representations as having an incorrigible social meaning that raises the moral stakes and opens the door to

\footnotetext{
${ }^{18}$ For a more substantive argument against the Gautian line of argument, see Patridge (2008).

19 Mia Consalvo makes a related point. She argues that we cannot simply bring our intuitions about what would be right and wrong in the actual world directly to bear on the world of games, though her focus is on a different phenomenon: in-game cheating. Consalvo (2005).
}

associated character assessments. In the final section, I offer an argument in support of incorrigibility in certain contexts, and then consider how my view can shed light on other video game controversies. Still, I do not think that the considerations that I present here are the only considerations that are morally salient, nor do I think that it follows that all-things-considered we should not enjoy playing any game with the kinds of representational details that I point out. That is, I do not here provide an ethics of video games, or even an ethics of single-player video game play. I think that the phenomena involved are far too complicated for such a project to be successful. My goal is to demonstrate that single-player game play itself, independent of the consequences of such game play, is open to moral assessment.

\section{Incorrigible social meaning and imaginative representations}

Let us begin with what I take to be an uncontroversial claim: imaginative representations can be more or less fictive or imaginative. We come to imaginative worlds armed with a host of background assumptions that are drawn from our knowledge of the actual world. For example, a fictional narrative might invite us to imagine that Barack Obama travels back in time to stop global climate change. In such a case, we are expected to bring our knowledge of the real Obama to the act of imagining, but to be epistemically flexible about such knowledge. Here epistemic flexibility requires that we be prepared to imagine that Obama is other than he is, namely that he has the property of having traveled in time to stop global climate change.

Epistemic flexibility, however, does not require complete epistemic openness. Sometimes we are justified in refusing to countenance an imaginative representation. For example, we might reasonably reject an otherwise imaginative representation because it does not cohere with our assumptions about folk psychology when, for example, we complain that "no real person would act like that."

Even stronger, sometimes we ought to reject an imaginative representation all-things-considered. To see this point, let us begin by considering that in some cases an otherwise imaginative representation is best understood as a critique of a real-world target. For example, the image of Obama going back in time to stop global climate change might act as a critique of his "god-like image." I take this point to be largely obvious, and uncontroversial. Moreover, insofar as imaginative imagery makes a comment about an actual person, it can be evaluated not only in terms of its aesthetic achievement, but also in terms of its accuracy. Again, I take this point to be uncontroversial. We might 
even find that an imaginative representation's accuracy, moral or otherwise, bears on its aesthetic achievement, say when we find a political cartoon hilarious because "it is so true." In other cases, however, the thing to do might be to reject an imaginative representation on moral grounds. To help illustrate this point, let us consider a cartoon image of Obama eating watermelon. In the context of the contemporary United States, such an image is properly interpreted as a racial insult. This is so because images like this have what I call an incorrigible social meaning. The meaning is incorrigible in that it is exceedingly difficult to overturn, and it is social in that this difficulty is explained by facts about a particular social reality.

How does indentifying the incorrigible social meaning of images help us to see the racist meaning of the cartoon of Obama eating watermelon? The United States has a peculiar history of slavery and racism, and images of individuals of African descent who are eating watermelon have played a significant part in this history. Primarily, these kinds of images have been used as a mechanism to insult and dehumanize African-Americans, and to bind racist Americans together through the practice of telling raciallydemeaning jokes. While the United States has made significant progress to overcome its racist past, racism is still a concern of paramount moral importance for the United States. That this kind of imagery has such an ignoble history, conjoined with the current reality of racism in the United States serves to stubbornly fix the meaning of the Obama cartoon. As a result, it would be very difficult for someone to use this kind of imagery in contemporary American culture in a way that avoids, or undermines its racist meaning. Such an interpretation would be, and it seems it ought to be, the first that occurs to those who are aware of this history. Even if the image's author were to claim that the image was not meant to be interpreted as a racist insult but as a compliment, those who are adequately aware of the history of this kind of imagery and adequately sensitive to the current plight of African Americans will refuse to see the image as the author intends, even while recognizing that the author's intentions were otherwise. Thus, there are limitations on what counts as a reasonable interpretation of such imagery. The author ought to have been aware of the incorrigible social meaning of this imagery, and if we are to take her at her word she is at best guilty of negligence. The same goes for a video game in which we are to navigate a representation of Obama through a watermelon patch. North-American audience members, at least, ought to see the meaning of this imagery as limited by their shared social-reality, and so see it as conveying a racist message. So, not only does epistemic flexibility not require epistemic openness, but even stronger, sometimes we ought to remain epistemically closed to certain interpretative possibilities because of moral facts on the ground.
None of this is to say that it would be impossible to undermine the meaning of imagery like this; certainly it is possible to do so. However, I suspect that just about any successful alteration of the meaning of Obama eating watermelon in the United States will be one that uses this kind of racist trope to make a distinctly anti-racist message. If I am right, then the range of possible meanings here is quite restricted because of the image's incorrigible social meaning. As a result, an author cannot simply employ such imagery to mean anything that she wants, nor can an audience member simply ignore the social meaning of such imagery.

Insofar as the incorrigibility of a representation is often contingent on social facts it is often, though not always, socially local. In another cultural context, images of Obama eating watermelon are unlikely to be properly interpreted as racially insulting. The particular insult that is raised by the particular image of Obama eating watermelon is culturally specific, and culturally contingent; in another cultural context it may be incomprehensible, or even a compliment. What this means is that the exact same image in a different cultural context will have a meaning that may be quite different and perhaps less incorrigible than its meaning in the context of the contemporary United States. So, determining if we should reject an imaginative image then might mean knowing quite a bit about the cultural context in which the image is deployed. Readers who find this series of examples mysterious because they are unaware of the social meaning that images of individuals of African descent who are eating watermelon have in the culture of United States are invited to consider images that have a similar kind of incorrigible social meaning that is local to their own cultural context. For example, a cartoon in which Obama is simianized probably has an incorrigible social meaning that is less local than an image of him eating watermelon. I have no doubt that all of us can construct many examples of imaginative representations that have such incorrigible social meanings. However, we should not infer from the fact that the meaning of certain images is made incorrigible by socially local facts that moral relativism follows. It does not. Consider the following general moral claim: racial oppression is morally pernicious, and we should not enjoy images that support such oppression. My claim is only that which particular images support such oppression will often be culturally local, and hence contingent. The general moral claim, however, is not. I offer a more substantive moral argument in the next section.

At this point, one might wonder what any of this has to do with actual video games played by actual gamers. After all, my motivating example, that of Barack Obama eating watermelon, is morally offensive because it targets a real person and so is to some extent not fictive or imaginative. 
Further, one might object that in many cases video game designers create fictional worlds that do not depict any real persons, and so the connection between the representation and reality that I rely on here does not obtain in the context of single-player video games, or at least not for the most part. But, I think that this worry paints too easy a gloss on what I think is a very complicated phenomenon. Consider, for example, that sometimes imaginative representations do not pick out any particular person, but nevertheless pick out groups of people. The depiction of Obama eating watermelon, for example, targets not just Obama, but the entire African-American community and perhaps all individuals of African descent. If the person depicted in the cartoon were not Obama but instead were a fictional African American, the image would still be racially insulting, even to Obama since Obama belongs to the group that the image targets. So, the fact that a single-player video game does not depict an actual person does not all by itself push such game play beyond the reach of my analysis.

\section{Incorrigible social meanings and moral evaluation}

Once we acknowledge that the social meaning of an otherwise imaginative representation can, in some cases, constrain our interpretation (this is the incorrigibility bit), we can see a way to make sense of the ethical assessment of single-player video game play that does not depend on the consequences of such game play. To help illustrate this, let us consider again the case of our friend's enjoyment of Custer's Revenge. As I argued earlier, the mere fact that our friend enjoys playing Custer's Revenge does not tell us very much about what to make of him morally. I think that there are at least three possible ways in which enjoyment here can signal a failing of character. First, as I mentioned earlier, his enjoyment might be an expression of unsavory attitudes, however inchoate. That is, our friend might be a racist or sexist despite his protestations otherwise. If this were true then it is a good bet that he enjoys the racist or sexist imagery for precisely this reason. Similarly, one's enjoyment of the cartoon of Obama eating watermelon might be best explained by the fact that one is racist. Still, as I said earlier, I accept that enjoying Custer's Revenge may not directly implicate one's moral attitudes. So, for the sake of argument, I will put this possibility to the side. Second, it might be that our friend does not recognize that these images have incorrigible social meanings. Some of my students, for example, are unaware of the social meaning that images of African-Americans eating watermelon have in the United States, because they are unaware of the history of this imagery. This kind of failing may be an epistemic failing, and may even be a moral failing assuming that we can make the case for the claim that we have a moral duty to know certain social facts. But, assuming that our friend knows how sexism and racism have played themselves out in the context of the contemporary United States, we can set this failing to the side as well. However, in setting these two kinds of failings aside, I do not mean to underplay the importance of such failings, and I am not denying that for any particular case that either of these failings provides the proper explanation. They might. It is just that they are not central for establishing what I am interested in here. My interest here is in responding to a different and possibly more challenging case: the gamer who does not have explicit, unsavory moral attitudes; one who knows the relevant social facts, but who fails to see why he shouldn't enjoy the game. It is this failing that is expressed by the challenge "Come on, it's only a game. You know I'm not racist or sexist." Is there anything that we can say to our friend to convince him that he ought not to enjoy representations like that, even if his enjoyment is not a direct reflection of unsavory moral attitudes? I think so, and I think that attending to the incorrigible social meaning of such imagery can help us see our way to a cogent moral criticism of our friend's enjoyment of Custer's Revenge. In such a case, it might be that our friend fails to see social meanings as incorrigible.

To help see the aforementioned possibility let us consider again the cartoon of Obama eating watermelon. Assuming that the proper interpretation of the political cartoon is one that invites its audience to find the image of Obama eating watermelon amusing or in some way enjoyable, then it invites its audience to share in a racist joke or comment. Americans, it seems, ought not to find this cartoon amusing. This is true whether the author recognizes it or not. The same goes for the video game in which one is to navigate a representation of Obama or any representation of an individual who appears to be of African descent through a watermelon patch. American gamers ought not to enjoy such representations, and similarly ought to refuse to see through these representations to the game mechanics. Such representations call for explicit rejection.

Similarly, the imagery of Custer's Revenge is worrisome at least in part because it targets women and Native Americans. In the actual world, women are the victims of a kind of systematic oppression that involves seeing them in certain kinds of ways, conceiving of them as certain kinds of creatures, and subjecting them to certain kinds of violence. Given this shared moral reality, it does not take much to see the representation of the female characters in this game as an extension of real-world moral phenomena, whatever the avowed intentions of the game designers, in the same way that the image of Obama eating watermelon is an extension of real-world racial phenomena. The game invites us to enjoy representations of women as objects of 
sexual violence in a way that does not undermine the morally worrisome social meaning of these images. In the United States, Native American women have the highest rate of rape of any other group of women; it is estimated that nearly 1 in 3 Native American women will be raped in her lifetime. ${ }^{20}$ Further, rape has traditionally been used as a tool of war and oppression against women. Given the history of the treatment of both Native Americans and women in the United States such an image cannot help but reference this history.

Still, we can imagine that our friend recognizes all this, and still responds "come on, it's only a game." Is there anything else we can say about why the meaning of this particular imagery is socially incorrigible while other representations of immorality are not? Though I do not hold out much hope for anything like a decision procedure here-in fact, I think that such determinations might in some cases be quite difficult, and that we will find that we have quite a bit of disagreement-it is worth pointing out that the kind of contextual details that are in play in the cases that I have mentioned are details about egregious, long-term, systematic denials of justice that are of a particular kind: oppression. Oppression is especially insidious because it denies individuals the respect that is due to one qua human. To be accorded access to resources for seeing oneself as fully human, rather than as subhuman, it is necessary to live a fully human life. Moreover, this is a need that, in the words of David Wiggins, "cannot be satisfied by one's own efforts." 21 Since it is others who deny them this dignity, it is others who must accord them this dignity. The fact that it is our shared social history, and it is we collectively (in these cases white Americans, or males as the case may be) who have denied individuals full access to such resources. Moreover, this denial has been achieved partly through the kinds of imaginative entertaining that the games in question invite us to adopt. This is what makes the images cited here particularly incorrigible, so that a friend who responds to our criticism of Custer's Revenge by claiming, "Come on, it's only a game; I'm not sexist." sees his imagining as just some random imagery detached from his own moral commitments, and detached from the moral facts on the ground. Such a failure is a failure both of sensitivity and of sympathy - sensitivity to the social meaning of the imagery, and sympathy with those who are the targets of such imagery. Sympathy requires us to inhabit the perspective of others, and to fail to see these representations as targeting others is to fail to adequately exhibit a properly sympathetic response in relation to a feature of current life that especially calls for sympathy; in this case, oppression. Sympathy in this

\footnotetext{
${ }^{20}$ Fears and Lydersen (2010).

21 Wiggins (1998).
}

context without a proper understanding of the social relevance of these images is no sympathy at all. As a result, one has the added duty to be cognizant of the incorrigible social meanings of these depictions. To pretend otherwise is to be tone deaf to an obvious feature of our moral reality. So, even if our friend does not have explicitly racist or sexist attitudes sufficient to justify the charge of racism or sexism, something has gone wrong with his attitudinal responses. He lacks a sensitivity to the meaning of this kind imagery and as a result fails to recognize the limitations of the imaginative content. To insist that one's imagination is one's own private affair, detached from one's own actual commitments and similarly detached from the contextual moral facts on the ground, amounts minimally, in this case, to a thumbing of one's nose at a requirement of solidarity with the victims of oppression. This is an obvious vice of character. So, it seems that minimally our friend is guilty of being racially and sexually insensitive.

Does attending properly to the incorrigible social meaning of imaginative representations avoid the problem of over-moralizing our game play? I think that it does. In many cases, the representational violence that we find in video games is presented so that it does not directly implicate our shared, moral reality. Though, on my view this is a contextual matter, and so in some contexts it might. As a result, the images lack an incorrigible social meaning and as a result are more interpretively flexible. We are often shooting aliens, or spies, or members of a competing faction. Whatever we are doing in these games is sufficiently insulated from our shared, moral reality so as to make the challenge "Come on, it's only a game!" a credible one. It is this insulation from the real world that makes the kind of associated character evaluations like "See how she has defended the citizens against the aggressive attack of the space aliens; she is certainly a good person." misplaced. But, as morally challenging representational content begins to reflect our actual, shared history of systematic moral violations like gender or racial oppression, this serves to limit the meaning of such imagery, and thereby open the door for associated character evaluations. One who enjoys playing games like Custer's Revenge may not be sexist, but still may lack the appropriate sensitivity to sexism. Such a lack of sensitivity might be a failure to see the relationship between the game's representation of members of an oppressed class and the actual oppression of such individuals, or it might be a failure to see such a connection as a reason to avoid enjoying such a representation. However we make sense of the particular failing of a particular player, the evaluative difference between the run-of-the-mill first-person shooter and games like Custer's Revenge is often best explained by the kind of representational wrong that the game invites us to enjoy. This is not to say that all-things-considered the 
game is not worthy of being played, it might be. My only claim here is that even when we determine that a game with morally worrisome content is worthy of being played, a virtuous gamer will refuse to enjoy the offending content because such content will bring to mind real-world, moral conditions. Similarly, such a gamer will at the very least refuse to see seamlessly through the representational content to the game mechanics on moral grounds. Such meanings demand our attention even if all-things-considered we determine that the representational wrong is slight enough to ignore for the sake of the game.

Further, attending to the incorrigible social meanings of video game imagery can help shed light on some other criticisms that have been raised against video games. Consider, for example, that these kinds of considerations are at least part of what bothers many about the prostitute scenario in Grand Theft Auto: San Andreas in which the gamer can procure the services of a prostitute only to kill her and take his money back, and the general sexualized representations of female characters in most video games. In the case of video game representations of women, part of why it is reasonable to see such imagery as representations of actual women is that they are nearly universally sexualized. This imagery has a meaning that is fixed by the actual practice of casting women in the role of objects of sexual pleasure and violence. I think that the same can be said of the notorious game RapeLay.

Further, it can help shed light on some current debates over games like Resident Evil $5 .^{22}$ Of particular worry is that the game's main character, Chris, is portrayed as a white westerner who must kill scores of African zombies. The image of Chris "unloading his pistol into hordes of African zombies" ${ }^{23}$ has a meaning that is contingent on the actual history of the colonization of Africa by westerners, so that an image of a white man shooting black Africans ought to bring to mind this troubling history. Moreover, the fact that black Africans are represented as zombies here raises another worry. The particular history of racial oppression of Africans involves stereotyping them as subhuman, a fact that gives the images in a game that portrays most of its subhuman characters, zombies, as African, a meaning that is fixed by this history. As a result, playing Resident Evil 5 puts many gamers in the position of enjoying a representation that just about any reasonable interpretation of which involves the reality of racial oppression. Just as the meaning of the image of the Obama eating watermelon is fixed by the history of racial oppression in the United States, the meaning of images of Africans as subhuman targets is fixed by a more global history of colonization and racial oppression.

\footnotetext{
22 Brophy-Warren (2009) and Jones (2009).

23 Brophy-Warren, ibid.
}

One might object that in Resident Evil 5 the social meaning of the offending imagery has been adequately undermined by the game designers, viz. there is a perfectly good reason for representing the zombies as African, since the game is set in Africa. Moreover, one might continue, the goal of the game is not to kill as many African zombies as you can, it is to save African villages, the continent of Africa, and even the world from a bio-terrorist group that has used a virus to turn Africans into zombies. Since the mission itself is a noble one by real-world standards, it is in the interest of most Africans, and since the action takes place in Africa, and since the real enemies are not the zombies but bio-terrorists, the otherwise problematic imagery is taken into account, and rendered morally neutral. ${ }^{24}$ As a result, it is reasonable to claim that the game designers have taken some measures to undermine the incorrigible meaning of images of white western males killing sub-human Africans.

I concede that an imaginative representation of African zombies could be employed in a way that is far less sensitive to the social meaning of such imagery. Still, given the history of racial oppression and colonization perpetrated by western countries against African nations, the depiction of characters as being of African descent and sub-human ought to bring to mind this actual history which involves in no small part the dehumanization of those of African descent. While one might not unreasonably make the claim that this kind of imagery harms those of African descent, this is not the claim that I am making here. My claim is only that it is in light of these histories that some images have an incorrigible meaning that game designers and gamers alike have a duty to take seriously, and it is at least an open question whether or not the designers of Resident Evil 5 have done so adequately. I think that they have not. Still, even if the game ultimately avoids the particular criticisms that I have here raised against it, it is clear that these are the kinds of considerations with which game designers and gamers must contend. In a globalized marketplace, game designers have a substantive moral duty to understand the incorrigible social meanings of the representations that they employ, which means that they have a duty to understand the cultures in which their products will be marketed.

Still, one might worry that the notion of an incorrigible social meaning does not address the issue of virtualpedophilia. How can talk about the incorrigible social meanings of imaginative representations make sense of our moral intuitions in a case like this? As I said at the outset,

\footnotetext{
${ }^{24}$ Mark Coeckelbergh, for example, argues that in assessing the representational content of single-player video games, we should ask ourselves if the activity would be justified in the actual world. See, Mark Coeckelbergh, ibid.
} 
such meanings are often, though not always local. Consider, for example that the meaning of the imagery of women that is found in most video games is likely not local, but global: the incorrigible social meaning of images of women is contingent on the actual, global history and current reality of women's oppression. In a world without gender oppression, such images will likely lose their incorrigible meanings. Still, the meaning of sexualized images of children may not be contingent in this way, since it seems clear that just about anyone who enjoys the thought of having sex with very young children exposes a flaw in her character and this fact does not seem to be contingent on facts about our moral reality. It seems that the same analysis can be given of games like RapeLay in which gamers are invited to enjoy not only representations of rape, but to enjoy simulating such activities. What this shows is that at least some meanings are not so obviously contingent on moral facts on the ground. Nevertheless, it is clear that the meaning of this imagery is significantly incorrigible so that anyone who wants to use sexualized imagery of children or rape will have to work to undermine this meaning. Still, as I mentioned earlier, the account that I offer here is not meant to be a complete analysis of the normativity of our single-person video game play. I think that there may be many other moral considerations that are salient for making moral judgments about what games we should play, including extrinsic ones. My aim here is to respond to the amoralist by providing a basis for making non-consequential moral judgments about such game play, and to do so in a way that does not over-moralize such game play. I think that I have done that here.

\section{References}

Brey, P. (1999). The ethics of representation and action in virtual reality. Ethics and Information Technology, 1, 5-14.

Brophy-Warren, J. (2009). 'Resident evil 5' reignites debate about race in videogames. Wall Street Journal. 12 March 2009.
Retrieved from http://online.wsj.com/article/SB123672060500987853.html. Accessed 23 June 2010.

Coeckelbergh, M. (2007). Violent computer games, empathy, and cosmopolitanism. Ethics and Information Technology, 9, 219-231.

Consalvo, M. (2005). Rule sets, cheating, and magic circles: Studying games and ethics. International Review of Ethics, 4, 7-12.

Fears, D. \& Lydersen, K. (2007). Native American women face high rape rate, report says: Tribes often lack funds and policing to patrol lands. Washington Post, 26 April 2007. Retrieved from http://www.washingtonpost.com/wp-dyn/content/article/2007/ 04/25/AR2007042502778.html, Accessed 23 June 2010.

Gaut, B. (2002). The ethical criticism of art. In J. Levinson (Ed.), Aesthetics and ethics. New York: Cambridge University Press.

Hursthouse, R. (1999). On virtue ethics. New York: Oxford University Press.

Jones, S.(2009). Resident Evil 5 (Xbox 360): They're coming to get you, Barbara. The Crispy Gamer. Retrieved from http://www. crispygamer.com/gamereviews/2009-03-12/resident-evil-5-xbox360.aspx. Accessed 23 June 2010.

Levy, N. (2002). Virtual child pornography: The eroticization of inequality. Ethics and Information Technology, 4, 319-323.

Luck, M. (2009). The gamer's dilemma: An analysis of the arguments for the moral distinction between virtual murder and virtual paedophilia. Ethics and Information Technology, 11, 31-36.

McCormick, M. (2001). Is it wrong to play violent video games? Ethics and Information Technology, 3, 277-287.

Patridge, S. (2008). Monstrous thoughts and the moral identity thesis. The Journal of Value Inquiry, 36, 181-193.

Raiter, M., \& Warner, D. (2005). Social Context in MassivelyMultiplayer Online Games (MMOGs): Ethical questions in shared space. International Review of Ethics, 4, 46-52.

Sicart, M. (2009). The ethics of computer games. Cambridge, MA: MIT Press.

Singer, P. (2007). Virtual vices. Project Syndicate, July 7, 2007. Retrieved from http://www.project-syndicate.org/commentary/ singer26/English. Accessed 23 Sept 2010.

Vellemen, D. (2008). Bodies, selves. American Imago, 65, 405-426.

Walton, K. (1997). Spelunking, simulation, and slime: On being moved by fiction. In M. Hjort \& S. Laver (Eds.), Emotion and the arts. New York: Oxford University Press.

Wiggins, D. (1998). Needs, values, and truth. New York: Oxford University Press.

Wonderly, M. (2008). A humean approach to assessing the moral significance of ultra-violent video games. Ethics and Information Technology, 10, 1-10. 